\title{
Exercise attenuates dexamethasone-induced hypertension through an improvement of baroreflex activity independently of the renin-angiotensin
} system

\author{
Paula B. Constantino ${ }^{\mathrm{a}, \mathrm{b}}$, Thiago J. Dionísioc ${ }^{\mathrm{c}}$, Francine Duchatsch ${ }^{\mathrm{a}, \mathrm{b}}$, Naiara A. Herrera ${ }^{\mathrm{a}, \mathrm{b}}$, \\ Josiane O. Duarte ${ }^{\mathrm{a}, \mathrm{d}}$, Carlos F. Santos ${ }^{\mathrm{c}}$, Carlos C. Crestani ${ }^{\mathrm{a}, \mathrm{d}}$, Sandra L. Amaral ${ }^{\mathrm{a}, \mathrm{b}, *}$ \\ a Joint Graduate Program in Physiological Sciences, PIPGCF UFSCar/UNESP, Rodovia Washington Luiz, km 235, Monjolinho, 676, São Carlos, SP, Brazil \\ b Department of Physical Education, Science Faculty, São Paulo State University (UNESP), Av. Eng. Luiz Edmundo Carrijo Coube, 14-01, Vargem Limpa, Bauru, SP, Brazil \\ ${ }^{c}$ Department of Biological Sciences, Bauru School of Dentistry, University of São Paulo, Alameda Octávio Pinheiro Brisolla, 9-75, Bauru, SP 17012-901, Brazil \\ d Laboratory of Pharmacology, School of Pharmaceutical Sciences, São Paulo State University (UNESP), Rodovia Araraquara Jaú, km 01 - s/n, Campos Ville, \\ Araraquara, SP 14800-903, Brazil
}

\section{A R T I C L E I N F O}

\section{Keywords:}

Exercise training

Glucocorticoids

Autonomic nervous system

Arterial pressure

Angiotensin II

\begin{abstract}
A B S T R A C T
Dexamethasone-induced hypertension may be caused by baroreflex alterations or renin-angiotensin system (RAS) exacerbation. Aerobic training has been recommended for hypertension treatment, but the mechanisms responsible for reduction of arterial pressure (AP) in dexamethasone (DEX) treated rats are still inconclusive.This study evaluated whether mechanisms responsible for training-induced attenuation of hypertension involve changes in autonomic nervous system and in RAS components. Rats underwent aerobic training protocol on treadmill or were kept sedentary for 8 weeks. Additionally, animals were treated with DEX during the last 10 days of exercise. Body weight (BW), AP and baroreflex activity were analyzed. Tibialis anterior (TA), soleus (SOL) and left ventricle (LV) were collected for evaluation of RAS components gene expression and protein levels. Dexamethasone decreased BW (20\%), caused TA atrophy (16\%) and increased systolic AP (SAP, 16\%) as well as decreased baroreflex activity. Training attenuated SAP increase and improved baroreflex activity, although it did not prevent DEX-induced BW reduction and muscle atrophy. Neither DEX nor training caused expressive changes in RAS components. In conclusion, exercise training was effective in attenuating hypertension induced by DEX and this response may be mediated by a better autonomic balance through an improvement of baroreflex activity rather than changes in RAS components.
\end{abstract}

\section{Introduction}

Despite its widespread use for allergies and inflammations, dexamethasone (DEX) induces several side-effects like hyperglycemia, muscle atrophy, baroreflex alterations, and hypertension [1-4]. Since hypertension is common in patients using glucocorticoid therapy [5], a better comprehension of the mechanisms responsible for this response is relevant in order to search for good strategies to control hypertension.

Renin angiotensin system (RAS) is an important system that controls arterial pressure (AP). Some evidence has suggested that DEX may increase RAS activity, although these results are still inconclusive. For instance, in vivo [6] and in vitro [7] studies have shown that DEX increases angiotensin II (Ang II) type 1 receptors (AT1) in vascular smooth muscle cells. DEX also increases vasoconstriction induced by
Ang II in coronary rings of sheep's offspring when pregnant sheep were treated with DEX, and causes cardiac remodeling via Ang II, which increases AP. These results suggest that negative changes in RAS may constitute an important pathophysiological mechanism underlying cardiovascular side-effects related to glucocorticoid treatment. Additionally, it has been shown that exposure to glucocorticoid during early gestation may induce alterations in postnatal cardiovascular physiology, such as decreased baroreflex sensitivity, sometimes earlier than changes in AP, thus suggesting that steroids may have several implications on nervous system $[8,9]$. However, up to the moment, there are no studies evaluating baroreflex activity after chronic exposition to DEX in adult rats.

On the other hand, regular aerobic exercise training is a well-established strategy to control AP [10]. Mechanisms responsible for AP lowering effects induced by training may include improvements in

\footnotetext{
* Corresponding author at: Department of Physical Education, Science Faculty, São Paulo State University (UNESP), Bauru, SP, Brazil.

E-mail address: slamaral@fc.unesp.br (S.L. Amaral).
} 
insulin sensibility, baroreflex gain, autonomic control to the heart, RAS activity, skeletal muscle angiogenesis and reductions of arterioles wallto-lumen ratio [11-14]. We have previously shown [15] that aerobic training significantly reduces AP in DEX-treated rats, and this response was associated with a better autonomic balance to the heart and skeletal muscle angiogenesis.

In addition, some studies have shown that aerobic training increases angiotensin 1-7 plasma content and its receptor as well as decreases AT1 receptor, Ang II plasma content and angiotensin converting enzyme (ACE) activity $[12,16]$. Therefore, changes in baroreflex gain as well as in RAS components may also constitute important mechanisms mediating a protector effect of exercise on DEX-induced hypertension. However, to the best of our knowledge, no study so far has investigated the effects of training on baroreflex activity and RAS components after DEX treatment. Therefore, this study evaluated whether mechanisms responsible for training-induced attenuation of hypertension involve changes in autonomic nervous system and in RAS components. We tested the hypothesis that aerobic training-induced attenuation of hypertension involves an improvement in baroreceptor activity and a better balance of RAS components.

\section{Experimental}

\subsection{Animals}

Experimental protocols were approved by the Committee for Ethical Use of Animals (CEUA, \#2012-02254) of the São Paulo State University (UNESP) (Araçatuba, SP, Brazil). All experiments were performed using 40 male Wistar rats (200-250 g) obtained from the Center for Research and Production Facilities of UNESP (Botucatu, SP, Brazil). All animals were housed in group cages in Animal Facility Maintenance from Faculty of Science, UNESP at Bauru, on a 12:12-h light-dark cycle and controlled temperature $\left(22^{\circ} \mathrm{C}\right)$. Food and water were provided ad libitum. Body weight (BW) was measured weekly during the exercise protocol and daily during DEX treatment.

After an adaptation period, animals underwent a maximal exercise test (Tmax) on the treadmill as previously published [1]. After the first Tmax, rats were randomly separated into 4 groups: 1 ) sedentary control (SC); 2) sedentary treated with DEX (SD); 3) trained control (TC) and 4) trained treated with DEX (TD). Trained groups underwent training protocol (50-60\% of their maximum capacity) on the treadmill, $1 \mathrm{~h} /$ day, 5 days/week for 70 days ( 60 days of training +10 days of training and DEX treatment) [15]. Tmax was repeated in all animals (sedentary and trained) at the end of 4 weeks ( $T \max 2$ ), in order to readjust the training load and after 8 weeks (Tmax3), to evaluate the efficacy of training protocol.

Both DEX-treated rat groups received daily injections of DEX (Decadron ${ }^{\circledast}, 1 \mathrm{mg} / \mathrm{kg}$ of body weight, i.p., at $9 \mathrm{am}$ ) during the last 10 days of training protocol. Control animals received daily injection of saline during the same period.

\subsection{Arterial pressure measurement}

After completing the experimental protocol, rats were anesthetized with tribromoethanol $(250 \mathrm{mg} / \mathrm{kg}$, i.p. $)$, and a catheter was inserted into the abdominal aorta through the femoral artery for cardiovascular parameters recording as published [15]. After surgery, rats were treated with a non-steroidal anti-inflammatory drug, flunixin meglumine $(0.025 \mathrm{mg} / \mathrm{kg}$, i.m. $)$, for postoperative analgesia. After $24 \mathrm{~h}$ of recovery, pulsatile AP was recorded using a pressure transducer connected to an amplifier (ADInstruments, Australia) and an acquisition board (PowerLab 4/35, ADInstruments, NSW, Australia) as published [15]. Mean arterial pressure (MAP), systolic arterial pressure (SAP), diastolic arterial pressure (DAP), and heart rate (HR) were derived from pulsatile AP recordings.

\subsection{Baroreflex analysis}

All animals were subjected to a 30-min period of basal cardiovascular parameters recording. After stabilization of AP signal, all rats received intravenous infusion of a selective $\alpha_{1}$-adrenoceptor agonist, phenylephrine $(70 \mu \mathrm{g} / \mathrm{mL}$ at $0.4 \mathrm{~mL} / \mathrm{min} / \mathrm{kg})$, and a nitric oxide donor, sodium nitroprusside $(100 \mu \mathrm{g} / \mathrm{mL}$ at $0.8 \mathrm{~mL} / \mathrm{min} / \mathrm{kg})$, using an infusion pump, as previously described [17]. Infusions of phenylephrine and sodium nitroprusside were randomized with 5 -min interval between infusions. Infusions lasted for $20-30 \mathrm{~s}$, resulting in the injection of a total dose of $9-14 \mu \mathrm{g} / \mathrm{kg}$ of phenylephrine and $26-40 \mu \mathrm{g} / \mathrm{kg}$ of sodium nitroprusside [17].

Baroreflex curves were constructed pairing MAP variations evoked by intravenous infusion of phenylephrine and sodium nitroprusside with reflex HR responses. Matching values of MAP and HR were plotted to generate sigmoid logistic functions for each rat, which were used to determine baroreflex activity, as previously published [17]. Baroreflex analyses using sigmoid curves were characterized through 5 parameters: (i) lower HR plateau $\left(P_{1}\right.$, bpm) (i.e., maximum reflex bradycardia); (ii) upper HR plateau $\left(P_{2}\right.$, bpm) (i.e., maximum reflex tachycardia); (iii) HR range (bpm) (i.e., difference between upper and lower plateau levels); (iv) median $\mathrm{AP}\left(\mathrm{BP}_{50}, \mathrm{mmHg}\right)$, which is the $\mathrm{MAP}$ at $50 \%$ of the HR range; and (v) average gain $(\mathrm{G}, \mathrm{bpm} / \mathrm{mmHg}$ ), which is the average slope of the curves between +1 and -1 standard derivations from $\mathrm{BP}_{50}$ [17].

To analyze bradycardia and tachycardia responses separately, HR values matching 10, 20, 30 and $40 \mathrm{mmHg}$ changes of MAP were calculated. Values were plotted to create linear regression curves for each rat and their slopes were compared to test changes in baroreflex gain [17].

\subsection{Real-time PCR procedures}

After conclusion of the experimental protocol, animals were euthanized through an overdose of anesthesia (Ketamine $160 \mathrm{mg} / \mathrm{kg}$ and Xylazine $20 \mathrm{mg} / \mathrm{kg}$ ). Left ventricle (LV), tibialis anterior (TA), soleus (SOL) muscles and adrenal gland (GA) were removed, cleaned, weighed, immediately frozen in dry ice and then stored at $-80^{\circ} \mathrm{C}$ for future protein and gene analysis. Tibia bone length was measured for muscle weight normalization. Tissue samples were quickly removed and collected under RNAse-free conditions for gene expression following the published protocol [15]. All samples were kept in RNAlater reagent (Ambion, Carlsbad, CA, USA) and maintained at $-80{ }^{\circ} \mathrm{C}$ until extraction. Total RNA was isolated using RNAeasy mini kit (Qiagen, Hilden, Germany). Once reconstituted, the quantity and quality of total RNA of each sample was verified in a spectrophotometer (Nanodrop 1000, Thermo Scientific, Walthan, Massachusets, USA) using wavelengths of $260 \mathrm{~nm}$ (A260) and $280 \mathrm{~nm}$ (A280), which provided information of the quantity and quality of RNA as previously published [15]. Relative quantification of RAS components was analyzed by means of real-time PCR reactions using the Taqman system (Applied Biosystems, Foster City, USA) in a thermocycler (ViiA ${ }^{\mathrm{TM}} 7$ Real-Time PCR System, Applied Biosystems, Foster City, USA). PCR reactions were performed in duplicate and water was used as a negative control. The quantitative mRNA expression was analyzed for AT1a (Rn01775763_gl), AT2 (Rn00560677_sl), ACE (Rn00561094_mL), ACE2 (Rn01416293_mL), MAS receptor (Rn00562673_sl), Renin (Rn00561847_mL), Angiotensinogen (Rn00593114_mL) and GAPDH (Hs9999905_m1). mRNA expression data were calculated as published [15].

\subsection{Western blot procedures}

For protein analysis, muscle samples were homogenized using a homogenizer (IKA ${ }^{\circledast}$ T18, Staufen, Germany) in RIPA solution (Cell Signaling Technology, USA). Before homogenization, $0.1 \%$ protease 
inhibitor cocktail (Pic, SigmaAldrich, USA) and 1\% phenylmethanesulfonyl fluoride (PMSF, Sigma Life Science, US) were added, as previously published [15]. Samples were centrifuged at $11,200 \times g$ for $5 \mathrm{~min}$ and the supernatant was collected and stored at $-20^{\circ} \mathrm{C}$ for future analysis. Bradford assays were used to determine protein concentration of the samples (Bio-Rad Kit, Protein Assay Standard II, CA) as previously published [1]. Absorbance values were determined using a spectrophotometric plate reader (BMG Labtech, Germany). Western blotting was performed according to previously published procedures [15]. In summary, samples containing $30-80 \mu \mathrm{g}$ of protein were separated using $8-12 \%$ denaturing polyacrylamide gels. These gels were then transferred to nitrocellulose membranes. Membranes were blocked with $3 \%$ bovine serum albumin (BSA) in Tris-buffered saline with Tween (TBS-T) for $2 \mathrm{~min}$. In a sequence, membranes (diluted in 3\% BSA) were incubated with primary antibody for $10 \mathrm{~min}$ using a SNAP i.d. ${ }^{\circledR}$ 2.0 Protein Detection system (Merck Millipore, Germany): polyclonal rabbit anti-renin (Cell Signaling Technology, \#5250, 1:1000), monoclonal rabbit anti-angiotensinogen (clone EPR 2931, Merck Millipore,\#MABC123, Germany, 1:1000), polyclonal rabbit anti-AT1 receptor (Merck Millipore, \#AB15552-50 $\mu \mathrm{L}$, Germany, 1:500), polyclonal rabbit anti-AT2 receptor (Merck Millipore, \#AB15554-50, Germany, 1:500), polyclonal rabbit anti-angiotensin (1-7) Mas receptor (Alomone Labs, \#AAR-013, Israel 1:200), monoclonal mouse anti-human CD 143 (ACE, AbD serotec, \#MCA2056, UK) and polyclonal rabbit anti-human ACE2 (Lifespan Biosciences, \#LS-C413153, 1:1000). Membranes were then washed and incubated with appropriate horseradish peroxidase conjugated secondary antibody (1\% BSA, Jackson Immuno Research) for $10 \mathrm{~min}$.

Signals were detected by enhanced chemiluminescence (Super signal ${ }^{\circledR}$ West Pico, Pierce) and captured on radiographic film, and bands of interest were analyzed using scanning densitometry (Scion Image Computer, 4.0.2). Group data were expressed as a percentage of the control group.

\subsection{Statistics}

All data were expressed as means \pm standard error of mean. Student's $t$ test was used to compare 2 groups. Two-way analysis of variance (ANOVA) was used to compare 4 groups, considering training as one factor and DEX treatment as another factor. Results with significant interactions were further analyzed by Tukey post hoc test using a software Sigma stat, 3.1.1.0. Significance level considered was $\alpha<0.05$.

\section{Results}

Animals' physical capacity was similar at the beginning of training between groups. After 8 weeks, both trained animals (treated or not) improved their physical capacity from $783 \pm 35 \mathrm{~s}$ to $1053 \pm 44 \mathrm{~s}$ $(\mathrm{p}<.001)$, while sedentary groups decreased from $785 \pm 37 \mathrm{~s}$ to $498 \pm 29 \mathrm{~s}(\mathrm{p}<.001)$.

Table 1 shows that DEX treatment of sedentary rats increased SAP $(+16 \%, \mathrm{p}<.001)$ and MAP $(+8 \%, \mathrm{p}=.012)$ compared with SC. On the other hand, training was effective in significantly attenuating the SAP increase after DEX treatment, compared with SD $(p=.04)$. Diastolic pressure was not affected neither by DEX nor training. In addition, DEX increased by $28 \%$ the HR of sedentary rats compared with SC ( $\mathrm{p}<.001$ ); however, training was not able to mitigate this response $(+29 \%$, TD $v s$ TC, $\mathrm{p}=.001$, Table 1$)$.

All animals gained weight during 8 weeks of training (Table 1). On the other hand, all DEX-treated animals, independently of training status, significantly lost BW $(-22 \%$ for SD, $\mathrm{p}=.016$ and $-20 \%$ for TD, $\mathrm{p}=.047$ ). BW of control groups remained unchanged during DEX treatment period.

DEX treatment resulted in a reduction of $16 \%(\mathrm{p}<.001)$ in TA muscle mass in sedentary rats and 20\% $(\mathrm{p}<.001)$ in trained rats
(Table 1). On the other hand, there were no effects of DEX treatment or training on LV and SOL muscles. Adrenal gland mass was 50\% reduced $(\mathrm{p}<.001)$ after DEX treatment in both sedentary and trained groups.

Results of the analysis of baroreflex activity are presented in Fig. 1 and Table 2. Nonlinear analysis of baroreflex activity indicated that treatment with DEX of sedentary rats reduced the G $(\mathrm{p}<.05)$, which means that it reduced baroreflex activity. This effect was not observed in animals that underwent exercise training on the treadmill (Fig. 1 and Table 2). When linear regression was analyzed, it was observed that treatment with DEX of sedentary rats impaired slope bradycardia response. Chronic training not only brought slope bradycardia response back to normal, but also it improved slope tachycardia response $(\mathrm{p}<.05)$, as shown in Table 2 .

In order to evaluate whether DEX could modify RAS components, gene expression (Fig. 2) and protein level (Fig. 3) were analyzed in myocardium, TA, and soleus muscles. When interactions for gene expression between treatment and training were analyzed, there was no effect of treatment and training in the myocardium for AGT, AT2 receptor, ACE2 and MAS receptor. However, there was an interaction between treatment and training effects for ACE and AT1a receptor mRNA. DEX treatment of sedentary rats did not significantly change any RAS component gene expression in myocardium (Fig. 2). Training of control rats increased ACE gene expression $(+96 \%, p=.006)$ and AT1a receptor gene expression $(89 \%, \mathrm{p}<.001)$ for TC $v s$ SC, respectively. However, these increases were significantly attenuated in trained and treated with DEX rats, as shown in Fig. 2 (ACE mRNA was $-51.8 \%$, and AT1a receptor mRNA was $-49.5 \%$ for TD $v s \mathrm{TC}, \mathrm{p}=.007$ and $\mathrm{p}=.001$, respectively).

In TA muscle it was observed an effect of treatment on AT1a receptor mRNA and MAS receptor mRNA whereas an effect of training was observed on AT2 mRNA. DEX treatment of sedentary rats significantly increased AT1a receptor mRNA $(+270 \%, \mathrm{p}=.004)$ and MAS receptor mRNA ( $+175 \%, p=.027$ ), compared with SC. ACE mRNA of SD rats was also higher than SC group, but the change was not significant. On the other hand, training attenuated the AT1a receptor mRNA increase $(\mathrm{p}=.130)$ and it did not avoid the increase in MAS receptor mRNA ( $+78 \%, \mathrm{p}=.013)$, both compared with TC $(\mathrm{p}<.05)$. In addition, trained and treated animals with DEX presented higher levels of AT2 receptor mRNA ( $+352 \%$ vs SD, $p=.012$ and $+142 \%$ vs TC, $\mathrm{p}=.033$, Fig. 2).

Finally, in SOL muscle, it was observed an effect of DEX treatment on AGT mRNA and MAS receptor mRNA, an effect of training on AT1a receptor mRNA, ACE mRNA and ACE2 mRNA and also interactions between training and DEX treatment on ACE mRNA. Fig. 2 shows that DEX treatment of sedentary rats increased AGT mRNA $(+87 \%$ vs SC, $\mathrm{p}=.012)$ and training did not attenuate this increase $(+155 \%$ vs TC, $\mathrm{p}=.009)$. Training of control rats increased AT1a receptor mRNA $(+32 \%$ vs SC, $\mathrm{p}=.027)$ and ACE2 mRNA $(+50 \%$ vs SC, $\mathrm{p}=.025)$. Trained and treated groups presented higher values of ACE mRNA $(+173 \%, \mathrm{p}<.001)$ and AT1a receptor mRNA $(+51 \%, \mathrm{p}=.09)$, both compared with SD rats. In addition, ACE mRNA of TD rats was also higher than in TC rats $(+72 \%, \mathrm{p}=.002$, Fig. 2$)$.

As observed in Fig. 3, DEX treatment of sedentary rats did not significantly alter any protein level of RAS components in myocardium. It was observed a training effect on AGT protein level. Fig. 3 shows that training increased AGT protein level in myocardium, independently of DEX treatment $(+31 \%$ and $+47 \%$, for TC $v s$ SC, $\mathrm{p}=.014$ and TD $v s$ SD, $\mathrm{p}<.001$, respectively). In TA muscle, an effect of treatment was observed on AT2 protein level. DEX treatment reduced AT2 receptor protein level $(-5 \%$ vs SC, $\mathrm{p}=.035)$, which was not attenuated by training $(-13 \%$, TD $v s$ TC, $\mathrm{p}=.01)$. Protein level of RAS components was not significantly affected neither by training nor DEX treatment in SOL muscle. 
Table 1

Values of body weight, left ventricle, adrenal glands, tibialis anterior and soleus muscles weight in sedentary and trained animals, treated with dexamethasone (DEX) or vehicle.

\begin{tabular}{|c|c|c|c|c|}
\hline & SC & SD & $\mathrm{TC}$ & TD \\
\hline \multicolumn{5}{|l|}{ Body weight } \\
\hline Before training & $232.5 \pm 5.6$ & $235.1 \pm 8.1$ & $235.4 \pm 4.4$ & $236.4 \pm 7$ \\
\hline After training & $374.4 \pm 7$ & $381.1 \pm 15$ & $358.5 \pm 12.5$ & $362.4 \pm 10.2$ \\
\hline Before DEX treatment & $382.6 \pm 7.1$ & $383.5 \pm 15.9$ & $363 \pm 13.6$ & $364.7 \pm 10.6$ \\
\hline After DEX treatment & $389.3 \pm 7.4$ & $297.5 \pm 10.3^{*}$ & $369 \pm 13.6$ & $290.3 \pm 7^{*}$ \\
\hline \multicolumn{5}{|l|}{ Muscle weight } \\
\hline Tibia $(\mathrm{cm})$ & $4.23 \pm 0.05$ & $4.2 \pm 0.07$ & $4.12 \pm 0.04$ & $4.21 \pm 0.06$ \\
\hline $\mathrm{LV}(\mathrm{g})$ & $0.77 \pm 0.02$ & $0.72 \pm 0.05$ & $0.75 \pm 0.03$ & $0.7 \pm 0.02$ \\
\hline LV/Tibia (mg/cm) & $183 \pm 4.5$ & $171.3 \pm 9.9$ & $182 \pm 7.4$ & $165.7 \pm 6.3$ \\
\hline TA $(g)$ & $0.72 \pm 0,03$ & $0.6 \pm 0.04^{*}$ & $0.72 \pm 0.03$ & $0.59 \pm 0.03^{*}$ \\
\hline TA/Tibia (mg/cm) & $169.6 \pm 7$ & $142 \pm 10.5^{*}$ & $175 \pm 8.7$ & $139 \pm 5.8^{*}$ \\
\hline SOL $(g)$ & $0.17 \pm 0.01$ & $0.16 \pm 0.01$ & $0.17 \pm 0$ & $0.16 \pm 0.01$ \\
\hline SOL/Tibia $(\mathrm{mg} / \mathrm{cm})$ & $40.6 \pm 1.6$ & $37.61 \pm 3$ & $42.33 \pm 1.1$ & $38.1 \pm 2.5$ \\
\hline $\mathrm{AG}(\mathrm{g})$ & $0.067 \pm 0.006$ & $0.033 \pm 0.003^{*}$ & $0.092 \pm 0.022$ & $0.036 \pm 0.003^{*}$ \\
\hline AG/Tibia (mg/cm) & $0.016 \pm 0.001$ & $0.008 \pm 0.001^{*}$ & $0.021 \pm 0.005$ & $0.008 \pm 0.001^{*}$ \\
\hline \multicolumn{5}{|l|}{ Arterial pressure } \\
\hline MAP (mmHg) & $106 \pm 3.5$ & $114.6 \pm 1.4^{*}$ & $107.8 \pm 2$ & $114.5 \pm 1.9$ \\
\hline $\mathrm{SAP}(\mathrm{mmHg})$ & $113.6 \pm 3.4$ & $131.8 \pm 3.7^{*}$ & $115.4 \pm 1.5$ & $122 \pm 1.4^{*}+$ \\
\hline $\mathrm{DAP}(\mathrm{mmHg})$ & $97.7 \pm 4.8$ & $100.8 \pm 2$ & $99.1 \pm 2.5$ & $106 \pm 2.5$ \\
\hline $\mathrm{HR}(\mathrm{b} / \mathrm{min})$ & $318 \pm 4$ & $406 \pm 20^{\prime \prime}$ & $324 \pm 14$ & $420 \pm 36^{*}$ \\
\hline
\end{tabular}

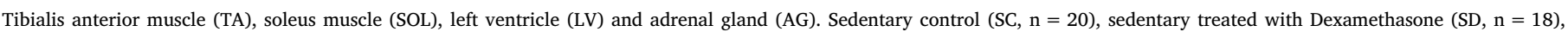
trained control (TC, $\mathrm{n}=20$ ) and trained treated with dexamethasone (TD, $\mathrm{n}=16)$. ANOVA 2-way:

Significance: * $v s$ respective control: SD $v s \mathrm{SC}$ or TD $v s \mathrm{TC} ;+v s$ respective sedentary: TC $v s$ SC or TD $v s \mathrm{SD}$; $<<.05$.

Sedentary

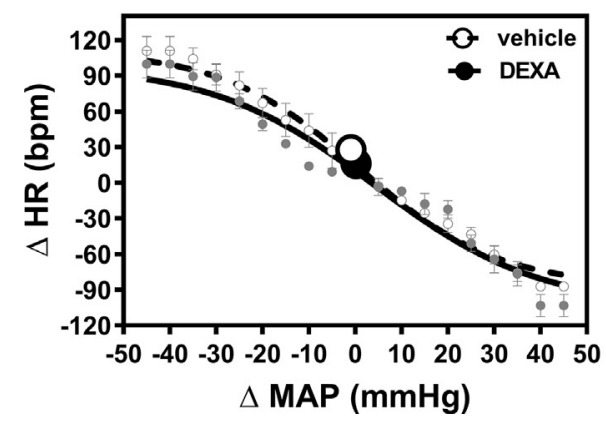

Trained

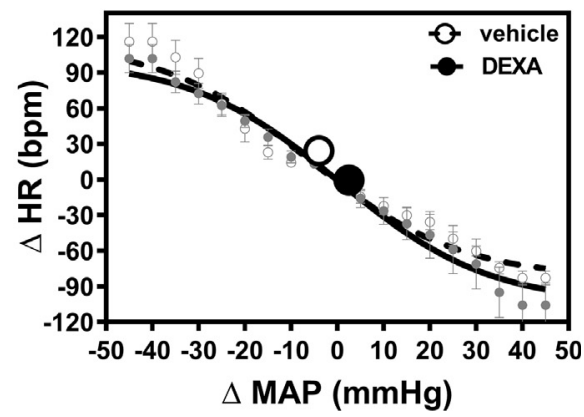

Fig. 1. Nonlinear regression analysis of the baroreflex correlating mean arterial pressure $(\triangle \mathrm{MAP})$ and heart rate $(\triangle \mathrm{HR})$ changes in sedentary and trained animals treated with dexamethasone (DEX) or vehicle. Symbols on sigmoid curves indicate the respective $\mathrm{BP}_{50}$. Increase and decrease in the MAP were induced by intravenous infusion of phenylephrine and sodium nitroprusside, respectively. Dotted line refers to vehicle group and solid line refers to DEX treated group.

Table 2

Parameters derived from nonlinear regression analysis of the baroreflex in sedentary and trained animals and treated with dexamethasone (DEX) or vehicle.

\begin{tabular}{|c|c|c|c|c|c|}
\hline Group & $\begin{array}{l}\mathrm{G} \\
(\mathrm{bpm} / \mathrm{mmHg})\end{array}$ & $\begin{array}{l}P_{1} \\
(\mathrm{bpm})\end{array}$ & $\begin{array}{l}P_{2} \\
(\mathrm{bpm})\end{array}$ & $\begin{array}{l}\text { HR range } \\
(\mathrm{bpm})\end{array}$ & $\begin{array}{l}\mathrm{BP}_{50} \\
(\mathrm{mmHg})\end{array}$ \\
\hline \multicolumn{6}{|l|}{ Sedentary } \\
\hline Vehicle & $-2.5 \pm 0.2$ & $-87 \pm 4$ & $111 \pm 11$ & $190 \pm 7$ & $-1 \pm 1$ \\
\hline Dexa & $-1.6 \pm 0.1^{*}$ & $-104 \pm 8$ & $99 \pm 11$ & $203 \pm 11$ & $-0.2 \pm 3$ \\
\hline \multicolumn{6}{|l|}{ Trained } \\
\hline Vehicle & $-1.9 \pm 0.1^{\#}$ & $-83 \pm 5$ & $116 \pm 11$ & $198 \pm 14$ & $-5 \pm 3$ \\
\hline Dexa & $-2.2 \pm 0.2^{\#}$ & $-105 \pm 12$ & $101 \pm 9$ & $212 \pm 18$ & $0.5 \pm 1$ \\
\hline Interaction & $F_{(1,19)}=12 \mathrm{p}<.001$ & $F_{(1,19)}=0.07 P>0.05$ & $F_{(1,19)}=2 P>0.05$ & $F_{(1,19)}=0.01 P>0.05$ & $F_{(1,19)}=1 P>0.05$ \\
\hline Treatment & $F_{(1,19)}=3 P>0.05$ & $F_{(1,19)}=5 \mathrm{p}<.04$ & $F_{(1,19)}=3 P>0.05$ & $F_{(1,19)}=0.5 P>0.05$ & $F_{(1,19)}=2 P>0.05$ \\
\hline Training & $F_{(1,27)}=0 P>0.05$ & $F_{(1,19)}=0.02 P>0.05$ & $F_{(1,19)}=1 P>0.05$ & $F_{(1,19)}=0.2 P>0.05$ & $F_{(1,19)}=0.6 P>0.05$ \\
\hline
\end{tabular}

Values are mean \pm SEM.

${ }^{*} P<.05$ vs respective group vehicle within same condition.

${ }^{\#} P<.05$ vs respective sedentary group.

Two-way ANOVA followed by Bonferroni post hoc test.

\section{Discussion}

The main findings of the present study were that chronic aerobic training was effective to decrease AP induced by DEX treatment and this response was partly explained by an improvement in baroreceptor activity rather than changes in RAS components.
It has been shown in the literature, and this present study confirmed, that BW reduction and skeletal muscle atrophy are common responses after chronic DEX treatment, which were not attenuated by aerobic exercise $[1,2,18,19]$.

Hypertension is an important side-effect observed both in humans [20] and animals treated with DEX $[3,4,6,8,15,21]$. However, the exact 

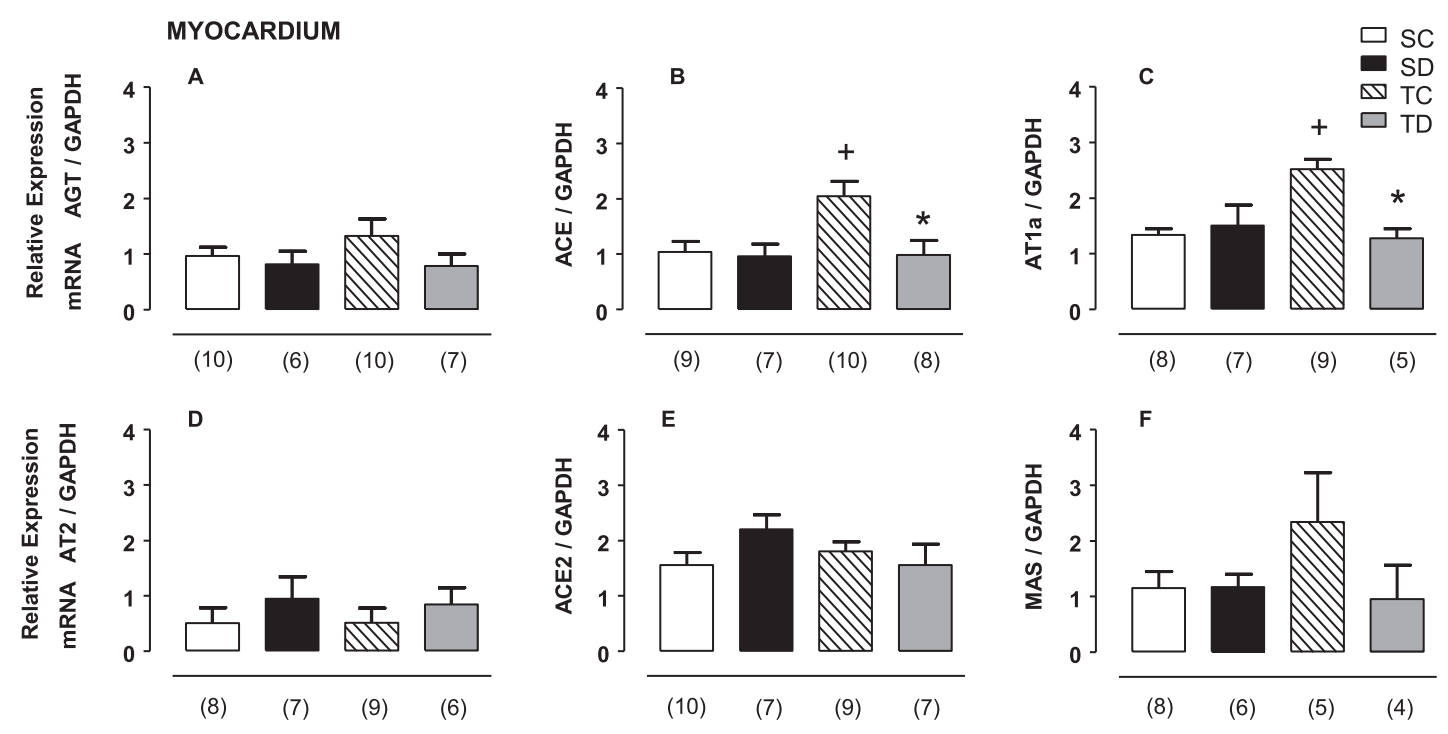

TIBIALIS ANTERIOR
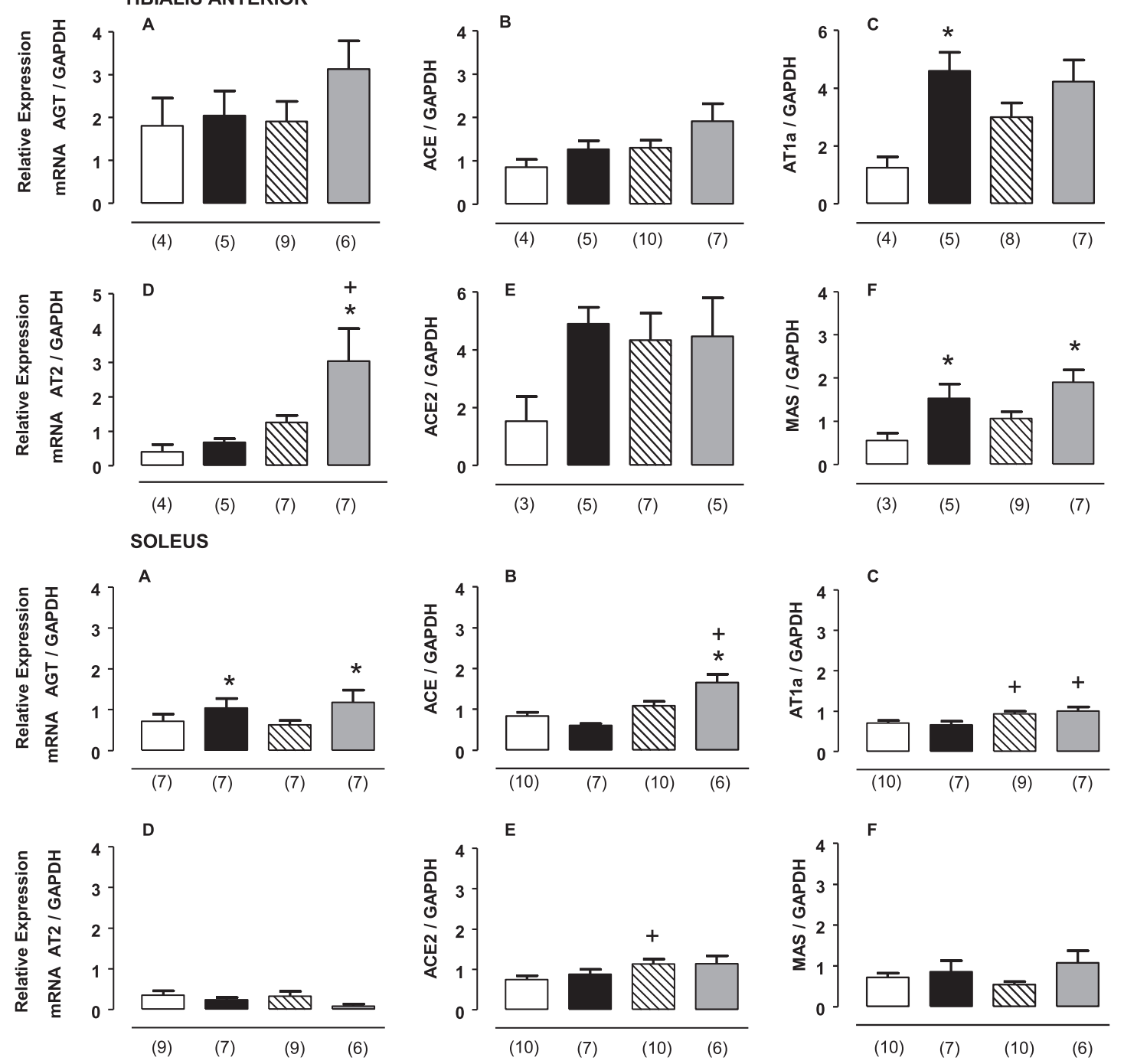

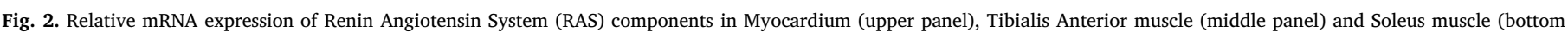

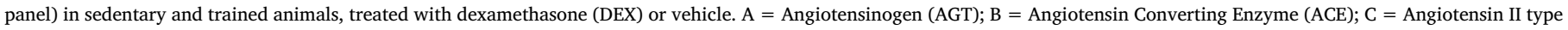

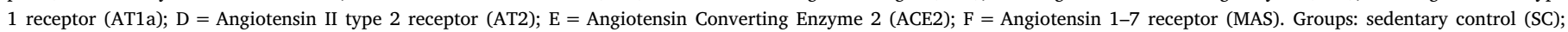

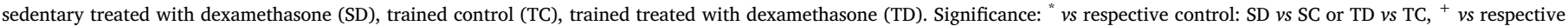
sedentary: SC $v s$ TC or SD $v s$ TD, $\mathrm{p}<.05$. 

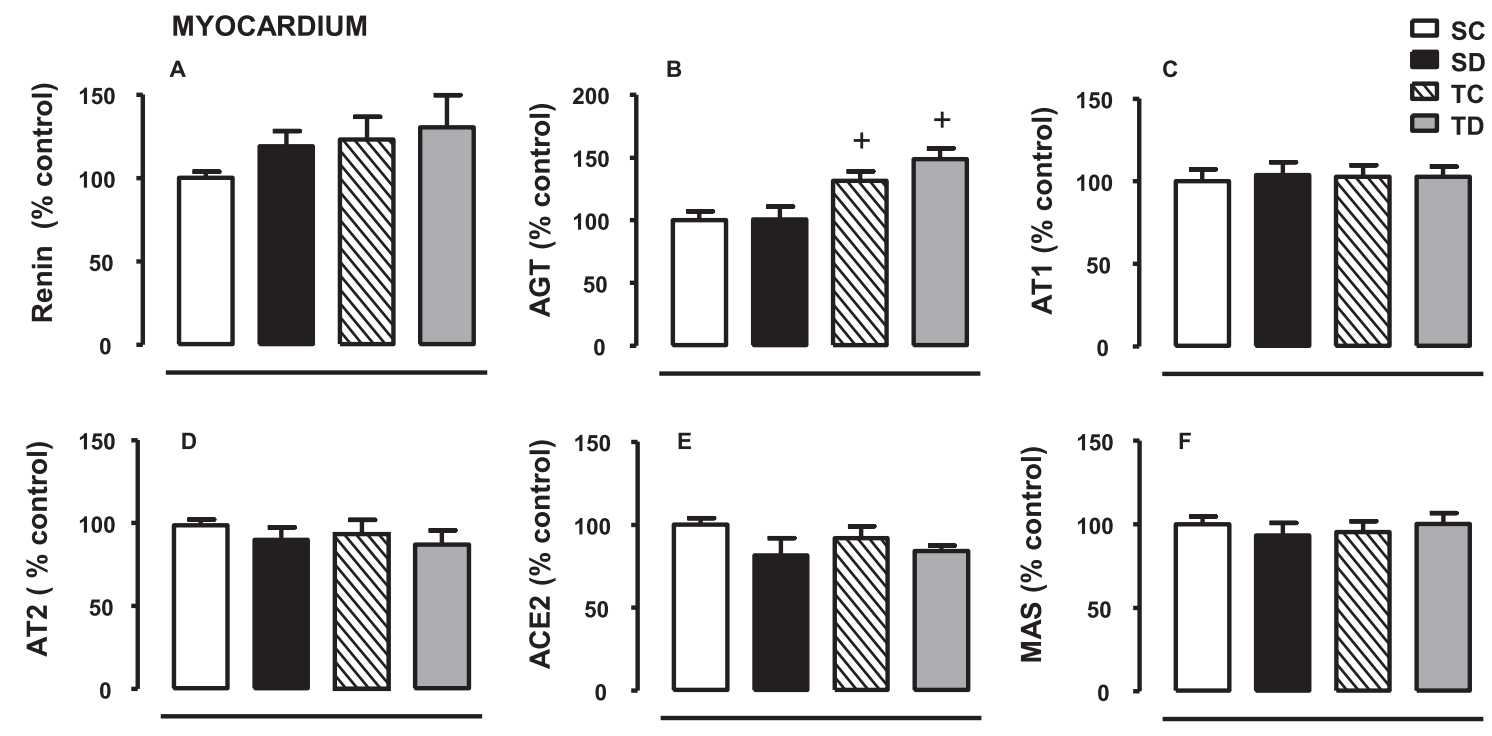

TIBIALIS ANTERIOR
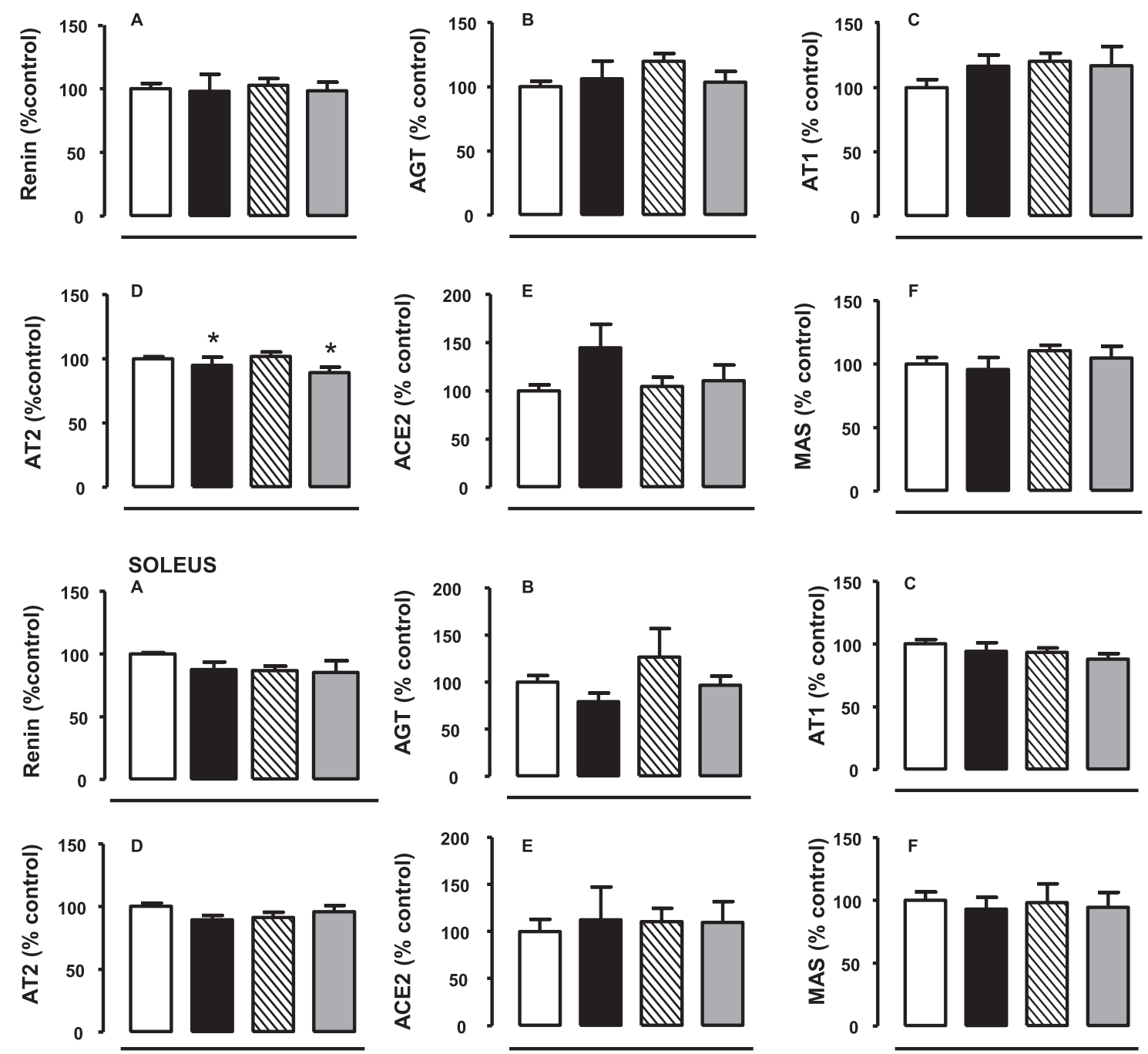

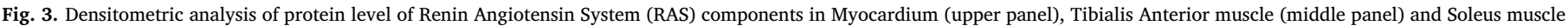

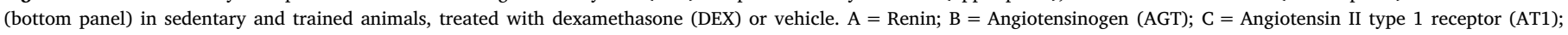

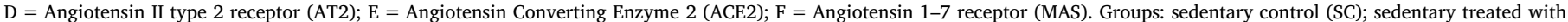

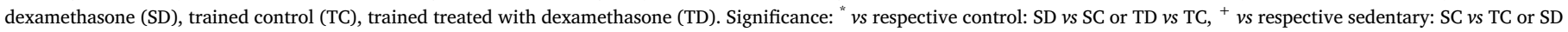
vs $\mathrm{TD}, \mathrm{p}<.05$. 
mechanism associated with this effect is not completely understood. Some authors have suggested an involvement of nitric oxide, oxidative stress and atrial natriuretic factor in this response [4,22,23]. In agreement, we recently demonstrated that chronic treatment with low doses of DEX increased AP, and this response was associated with an autonomic imbalance to the heart and skeletal muscle rarefaction [15]. Nevertheless, baroreflex activity was not evaluated in that study. Therefore, in the present study we evaluated the baroreflex activity in order to further investigate possible mechanisms underlying the effects of DEX and training on arterial pressure. Impairment of baroreflex activity has been implicated in etiology and development of hypertension [24]. In the present work, nonlinear analysis of baroreflex activity indicated that DEX treatment in sedentary animals reduced the curve slope, thus suggesting a reduction in baroreflex activity. In addition, linear regression revealed a reduction of slope bradycardia response. Considering the role of baroreflex changes in the pathogenesis of hypertension, the present results suggest, for the first time, that impairment of this reflex cardiovascular regulation could play a role in DEXinduced hypertension. Impairment of baroreflex activity is also associated with overactivity of the sympathetic tone (in agreement with previous results), indicating that damage in baroreflex activity may also mediate resting tachycardia evoked by DEX. Previous results have shown that prenatal exposure to DEX induces hypertension in adult sheeps, which may be associated with autonomic dysfunctions [8] and that, in this model, baroreflex alterations may appear before any change in AP [9].

Activation of RAS has also been implicated in DEX-induced hypertension. It has been shown that pre-treatment with SQ14225 (ACE inhibitor) attenuated the increase in AP induced by DEX treatment for 7 days [21], and that treatment with losartan lowered AP after DEX treatment [6], thus suggesting that RAS could be one of the mechanisms responsible for DEX-induced hypertension. For this reason, we analyzed gene expression and protein levels of RAS components in heart and skeletal muscles. Results of the present study revealed that in DEX treatment group (SD) there were no significant changes in gene expression of RAS components in the myocardium, however, we observed that DEX determined an increase in gene expression of AT1a receptor and MAS in TA muscle and increased AGT mRNA in SOL, but these responses were not confirmed when the protein analysis was done. Cell culture studies have shown that DEX causes a time- and dose-dependent increase in mRNA expression of ACE and AT1 receptor [25]. Also, in cell culture, AGT may increase after DEX treatment [26]. The only alteration in protein levels observed in the present study was that DEX treatment (SD group) reduced AT2 receptor protein level in TA muscle, which might be an important result, since AT2 contributes to the vasodilator response; however we believe that this isolated response was very weak to contribute to increase AP. To the best of our knowledge, the present study is the first reporting the effects of DEX in RAS components in the skeletal and cardiac muscles and we can suggest that there were no significant responses that could justify any AP increase. Future studies should investigate plasma level of Ang II and Ang (1-7) in this model of hypertension.

The results of this present study revealed that exercise training, performed previously to DEX administration, was effective in attenuating SAP increase evoked by DEX treatment. Low-intensity exercise training has been widely recommended as coadjuvant of hypertension treatment [10], mainly because of the acute and chronic exercise effects in decreasing AP. Several mechanisms have been suggested for this effect, such as reduction of peripheral vascular resistance $[11,27,28]$, increase of NO bioavailability $[29,30]$, reduction of sympathetic nerve activity [14] and improvement of baroreflex control[14].

We have previously shown that exercise training improved the autonomic balance to the heart, decreased sympathetic vascular modulation and augmented the skeletal muscle microcirculation in parallel to the reduced arterial pressure in rats treated with DEX [15], and these results were important to understand the preventive role of exercise training in counteracting DEX- induced hypertension. Interestingly, the results of the present work revealed that continuous aerobic preconditioning prevented DEX-evoked baroreflex alterations, for instance training improved the average gain, prevented the decreases in slope bradycardia response and also increased slope tachycardia response. Taken together, we believe that these responses may constitute an important mechanism mediating the beneficial effects of exercise in DEX-treated animals.

Nevertheless, it seems that the mechanisms underlying exercise-induced attenuation of hypertension did not involve RAS. Indeed, trained animals that received DEX treatment showed a significant reduction of ACE gene expression and AT1 receptor compared with trained controls (LV), but the expression of these components was not different from that observed in treated sedentary animals. On the other hand, TA muscle of treated and trained animals showed higher levels of AT2 receptor and MAS mRNA, which would be an important response, but these genes were not transcribed into protein. Protein results also showed that training failed to reverse the reduction of AT2 receptor protein level induced by DEX. In SOL muscle, training increased the amount of ACE2 and AT1 receptor mRNA. When trained rats were treated with DEX, increases in AT1 receptor, AGT and ACE mRNA were observed, however, these components were not transcribed into protein.

In conclusion, the present results indicate that continuous aerobic pre-conditioning was effective in attenuating hypertension induced by chronic treatment with DEX. These findings indicate that this response is mainly mediated by a better autonomic balance through an improvement of baroreflex activity rather than changes in RAS.

\section{Acknowledgments}

This study was supported by São Paulo Research Foundation (FAPESP grants \#2011/21522-0 to SLA and \#2012/14376-0 to CCC). PBC, NAH and FD were recipients of scholarships from FAPESP (\#2012/19722-3, \# 2014/18177-7 and \#2014/23050-6, respectively). TJD was a recipient of a scholarship from the National Council for Scientific and Technological Development (CNPq, process \# 140206/ 2011-6). We gratefully acknowledge the technical assistance of Lidiane M. Souza (FAPESP \# 2012/03816-9).

\section{References}

[1] M. Barel, O.A. Perez, V.A. Giozzet, A. Rafacho, J.R. Bosqueiro, S.L. do Amaral, Exercise training prevents hyperinsulinemia, muscular glycogen loss and muscle atrophy induced by dexamethasone treatment, Eur. J. Appl. Physiol. 108 (5) (2010) 999-1007.

[2] T.J. Dionisio, J.C. Louzada, B.A. Viscelli, E.J. Dionisio, A.M. Martuscelli, M. Barel, O.A. Perez, J.R. Bosqueiro, D.T. Brozoski, C.F. Santos, S.L. Amaral, Aerobic training prevents dexamethasone-induced peripheral insulin resistance, Horm. Metab. Res. 46 (7) (2014) 484-489.

[3] M. Dodic, A.T. McAlinden, A.J. Jefferies, E.M. Wintour, M.L. Cock, C.N. May, R.G. Evans, K.M. Moritz, Differential effects of prenatal exposure to dexamethasone or cortisol on circulatory control mechanisms mediated by angiotensin II in the central nervous system of adult sheep, J. Physiol. 571 (3) (2006) 651-660.

[4] S.L. Ong, H. Vohra, Y. Zhang, M. Sutton, J.A. Whitworth, The effect of alpha-lipoic acid on mitochondrial superoxide and glucocorticoid-induced hypertension, Oxid. Med. Cell. Longev. (2013) 517045.

[5] J.A. Whitworth, Mechanisms of glucocorticoid-induced hypertension, Kidney Int. Suppl. 31 (5) (1987) 1213-1224.

[6] S.G. Roy, P. De, D. Mukherjee, V. Chander, A. Konar, D. Bandyopadhyay, A. Bandyopadhyay, Excess of glucocorticoid induces cardiac dysfunction via activating angiotensin II pathway, Cell. Physiol. Biochem. 24 (1-2) (2009) 1-10.

[7] I.G. Bogdarina, P.J. King, A.J. Clark, Characterization of the angiotensin (AT1b) receptor promoter and its regulation by glucocorticoids, J. Mol. Endocrinol. 43 (2) (2009) 73-80.

[8] M. Dodic, A. Peers, J.P. Coghlan, C.N. May, E. Lumbers, Z. Yu, E.M. Wintour, Altered cardiovascular haemodynamics and baroreceptor-heart rate reflex in adult sheep after prenatal exposure to dexamethasone, Clin. Sci. 97 (1) (1999) 103-109.

[9] J.L. Segar, R.D. Roghair, E.M. Segar, M.C. Bailey, T.D. Scholz, F.S. Lamb, Early gestation dexamethasone alters baroreflex and vascular responses in newborn lambs before hypertension, Am. J. Physiol. Regul. Integr. Comp. Physiol. 291 (2) (2006) R481-488.

[10] G. Mancia, R. Fagard, K. Narkiewicz, J. Redon, A. Zanchetti, M. Bohm, 
T. Christiaens, R. Cifkova, G. De Backer, A. Dominiczak, M. Galderisi, D.E. Grobbee, T. Jaarsma, P. Kirchhof, S.E. Kjeldsen, S. Laurent, A.J. Manolis, P.M. Nilsson, L.M. Ruilope, R.E. Schmieder, P.A. Sirnes, P. Sleight, M. Viigimaa, B. Waeber, F. Zannad, 2013 ESH/ESC Guidelines for the management of arterial hypertension: the Task Force for the management of arterial hypertension of the European Society of Hypertension (ESH) and of the European Society of Cardiology (ESC), J. Hypertens. 31 (7) (2013) 1281-1357.

[11] S.L. Amaral, L.C. Michelini, Effect of gender on training-induced vascular remodeling in SHR, Braz. J. Med. Biol. Res. 44 (9) (2011) 814-826.

[12] J.V. Felix, L.C. Michelini, Training-induced pressure fall in spontaneously hypertensive rats is associated with reduced angiotensinogen mRNA expression within the nucleus tractus solitarii, Hypertension 50 (4) (2007) 780-785.

[13] M.T. Jordao, F.V. Ladd, A.A. Coppi, R.P. Chopard, L.C. Michelini, Exercise training restores hypertension-induced changes in the elastic tissue of the thoracic aorta, J. Vasc. Res. 48 (6) (2011) 513-524.

[14] M.C. Laterza, L.D. de Matos, I.C. Trombetta, A.M. Braga, F. Roveda, M.J. Alves, E.M. Krieger, C.E. Negrao, M.U. Rondon, Exercise training restores baroreflex sensitivity in never-treated hypertensive patients, Hypertension 49 (6) (2007) 1298-1306.

[15] N.A. Herrera, I. Jesus, A.L. Shinohara, T.J. Dionisio, C.F. Santos, S.L. Amaral, Exercise training attenuates dexamethasone-induced hypertension by improving autonomic balance to the heart, sympathetic vascular modulation and skeletal muscle microcirculation, J. Hypertens. 34 (10) (2016) 1967-1976.

[16] T. Fernandes, N.Y. Hashimoto, F.C. Magalhaes, F.B. Fernandes, D.E. Casarini, A.K. Carmona, J.E. Krieger, M.I. Phillips, E.M. Oliveira, Aerobic exercise traininginduced left ventricular hypertrophy involves regulatory MicroRNAs, decreased angiotensin-converting enzyme-angiotensin ii, and synergistic regulation of angiotensin-converting enzyme 2-angiotensin (1-7), Hypertension 58 (2) (2011) $182-189$.

[17] S.A. Engi, F.C. Cruz, R.M. Leao, L.C. Spolidorio, C.S. Planeta, C.C. Crestani, Cardiovascular complications following chronic treatment with cocaine and testosterone in adolescent rats, PloS One 9 (8) (2014) e105172.

[18] A.M. Ahtikoski, E.M. Riso, S.O. Koskinen, J. Risteli, T.E. Takala, Regulation of type IV collagen gene expression and degradation in fast and slow muscles during dexamethasone treatment and exercise, Pflugers Archiv: Eur. J. Appl. Physiol. 448 (1) (2004) 123-130.

[19] C.H. Pinheiro, W.M. Sousa, Filho, J. Oliveira Neto, J. Marinho Mde, R. Motta Neto, M.M. Smith, C.A. Silva, Exercise prevents cardiometabolic alterations induced by chronic use of glucocorticoids, Arq. Bras. Cardiol. 93 (4) (2009) 392-400.
[20] D.J. Brotman, J.P. Girod, M.J. Garcia, J.V. Patel, M. Gupta, A. Posch, S. Saunders, G.Y. Lip, S. Worley, S. Reddy, Effects of short-term glucocorticoids on cardiovascular biomarkers, J Clin. Endocrinol. Metab. 90 (6) (2005) 3202-3208.

[21] H. Suzuki, M. Handa, K. Kondo, T. Saruta, Role of renin-angiotensin system in glucocorticoid hypertension in rats, Am. J. Physiol. 243 (1) (1982) E48-E51.

[22] N. Guarino, H. Shima, P. Puri, Cardiac gene expression and synthesis of atrial natriuretic peptide in the nitrofen model of congenital diaphragmatic hernia in rats: effect of prenatal dexamethazone treatment, J. Pediatr. Surg. 36 (10) (2001) 1497-1501.

[23] T. Wallerath, K. Witte, S.C. Schafer, P.M. Schwarz, W. Prellwitz, P. Wohlfart, H. Kleinert, H.A. Lehr, B. Lemmer, U. Forstermann, Down-regulation of the expression of endothelial NO synthase is likely to contribute to glucocorticoid-mediated hypertension, Proc. Natl. Acad. Sci. U.S.A. 96 (23) (1999) 13357-13362.

[24] G. Grassi, F. O. Trevano, G. Seravalle, F. Scopelliti, G. Mancia, Baroreflex function in hypertension: consequences for antihypertensive therapy, Prog. Cardiovasc. Dis. 48 (6) (2006) 407-415.

[25] M.L. Barreto-Chaves, I. Aneas, J.E. Krieger, Glucocorticoid regulation of angiotensin-converting enzyme in primary culture of adult cardiac fibroblasts, Am. J. Physiol. Regul. Integr. Comp. Physiol. 280 (1) (2001) R25-32.

[26] J. Aubert, C. Darimont, I. Safonova, G. Ailhaud, R. Negrel, Regulation by glucocorticoids of angiotensinogen gene expression and secretion in adipose cells, Biochem. J. 328 (Pt 2) (1997) 701-706.

[27] A.J. Maiorana, L.H. Naylor, A. Exterkate, A. Swart, D.H. Thijssen, K. Lam, G. O'Driscoll, D.J. Green, The impact of exercise training on conduit artery wall thickness and remodeling in chronic heart failure patients, Hypertension 57 (1) (2011) 56-62.

[28] L.V. Rossoni, R.A. Oliveira, R.R. Caffaro, M. Miana, D. Sanz-Rosa, M.K. Koike, S.L. Do Amaral, L.C. Michelini, V. Lahera, V. Cachofeiro, Cardiac benefits of exercise training in aging spontaneously hypertensive rats, J. Hypertens. 29 (12) (2011) 2349-2358.

[29] V.A. Barbosa, T.F. Luciano, S.O. Marques, M.F. Vitto, D.R. Souza, L.A. Silva, J.P. Santos, J.C. Moreira, F. Dal-Pizzol, F.S. Lira, R.A. Pinho, C.T. De Souza, Acute exercise induce endothelial nitric oxide synthase phosphorylation via Akt and AMPactivated protein kinase in aorta of rats: Role of reactive oxygen species, Int. J. Cardiol. 167 (6) (2013) 2983-2988.

[30] M. Cocks, C.S. Shaw, S.O. Shepherd, J.P. Fisher, A.M. Ranasinghe, T.A. Barker, K.D. Tipton, A.J. Wagenmakers, Sprint interval and endurance training are equally effective in increasing muscle microvascular density and eNOS content in sedentary males, J. Physiol. 591 (3) (2013) 641-656. 